\title{
Prior or Concomitant Drinking of Vegetable Juice with a Meal Attenuates Postprandial Blood Glucose Elevation in Healthy Young Adults
}

\author{
Noriaki Kasuya1*, Megumi Okuyama1, Kazutaka Yoshida2*\#, Satoshi Sunabori2, \\ Hiroyuki Suganuma', Isamu Murata1, Yutaka Inoue', Ikuo Kanamoto \\ ${ }^{1}$ Laboratory of Drug Safety Management, Faculty of Pharmaceutical Sciences, Josai University, Saitama, Japan \\ ${ }^{2}$ Innovation Division, KAGOME CO. LTD., Tochigi, Japan \\ Email: "Kazutaka_Yoshida@kagome.co.jp
}

Received 24 June 2016; accepted 25 July 2016; published 28 July 2016

Copyright (C) 2016 by authors and Scientific Research Publishing Inc.

This work is licensed under the Creative Commons Attribution International License (CC BY). http://creativecommons.org/licenses/by/4.0/

(c) (i) Open Access

\begin{abstract}
Controlling postprandial blood glucose levels can prevent and improve lifestyle-related diseases. We aimed to evaluate the effects of a commercially available vegetable juice, which is a convenient alternative to vegetables, on postprandial glucose elevation. In test 1 , we confirmed the appropriate timing to consume the vegetable juice $(200 \mathrm{~mL})$, and demonstrated that postprandial glucose elevation was attenuated by drinking the vegetable juice with or before the experimental meal. The change in maximum concentration $\left(\Delta \mathrm{C}_{\max }\right)$ of blood glucose was the lowest when the vegetable juice was consumed at $30 \mathrm{~min}$ before the meal. In test 2 , we confirmed the necessary ingestion volumes of vegetable juice (range: $68.5-274 \mathrm{~mL}$ ) for attenuating the response to $50 \mathrm{~g}$ of carbohydrates. After drinking $200 \mathrm{~mL}$ of vegetable juice, the $\Delta \mathrm{C}_{\max }$ and incremental area under the curve values for blood glucose were significantly lower than those for after drinking the same volume of water $(p<0.05)$. However, a greater volume of vegetable juice did not provide an additive effect. Our results suggest that approximately $200 \mathrm{~mL}$ of vegetable juice at $30 \mathrm{~min}$ before meals is the most effective method for using vegetable juice to suppress postprandial blood glucose elevation. Stimulation of insulin secretion due to the pre-meal vegetable juice intake may contribute to this effect, although further studies are needed to identify the detailed mechanism for the attenuation.
\end{abstract}

\section{Keywords}

Pre-Meal, Vegetable Juice, Carbohydrate, Postprandial Blood Glucose, Insulin

\footnotetext{
"These authors contributed equally to this work.

${ }^{*}$ Corresponding author.
}

How to cite this paper: Kasuya, N., Okuyama, M., Yoshida, K., Sunabori, S., Suganuma, H., Murata, I., Inoue, Y. and Kanamoto, I. (2016) Prior or Concomitant Drinking of Vegetable Juice with a Meal Attenuates Postprandial Blood Glucose Elevation in Healthy Young Adults. Food and Nutrition Sciences, 7, 797-806. http://dx.doi.org/10.4236/fns.2016.79080 


\section{Introduction}

Diabetes is a major non-communicable disease that is caused by impaired insulin production. The number of patients with diabetes has been rapidly increasing worldwide, and it is expected to surpass 439 million adults by 2030 [1]. Moreover, extensive studies have indicated that uncontrolled diabetes may cause serious complications, such as cardiovascular disease, neuropathy, nephropathy, and retinopathy [2]-[6]. Therefore, diabetes prevention is an important public health concern.

The development of diabetes is highly correlated with lifestyle and diet, and poor control of postprandial blood glucose levels is thought to result in elevated fasting blood glucose levels and worsened diabetic status [7]. Moreover, rapid increases in postprandial blood glucose levels are considered a risk factor for obesity and cardiovascular disease [8]-[10]. Therefore, controlling postprandial blood glucose levels may be used to prevent and improve diabetes and other lifestyle-related diseases. Thankfully, a proper diet can control postprandial blood glucose levels and prevent the development of diabetes and its complications. Previous studies revealed that the consumption of high-Glycemic Index (GI) foods, which produce a relatively large increase in postprandial blood glucose levels, was a risk factor for lifestyle-related diseases, such as obesity, diabetes, and cardiovascular diseases [11]-[14]. Moreover, a large body of evidence indicates that the consumption of low-GI foods can significantly improve metabolic disorders [15]-[17].

In this context, vegetables contain large amounts of dietary fiber and are considered low-GI foods. Furthermore, it has recently been reported that eating a vegetable salad (which contains cabbage, tomato, and other vegetables) before consuming carbohydrates can suppress postprandial blood glucose elevation [18]-[20]. The main mechanism for this effect is thought to be the vegetables' dietary fiber inhibiting the absorption of carbohydrates.

Although several studies have demonstrated that vegetable salads can exert beneficial effects on postprandial blood glucose elevation, there are no reports regarding the same effect being elicited by processed food products that are made from vegetables. Nevertheless, drinking vegetable juice is one of the most convenient alternatives to eating vegetables. Thus, if vegetable juice consumption also suppresses postprandial blood glucose elevation, it would be simpler to control postprandial blood glucose levels in daily life. Therefore, we evaluated the effects of a commercially available vegetable juice on postprandial blood glucose elevation in healthy young adults.

\section{Materials and Methods}

\subsection{Vegetable Juice and Experimental Meal}

This study used a commercially available mixed vegetable juice that is named "Kagome Yasai-ichinichikoreippon” (KAGOME CO., LTD. Nagoya, Japan). This juice consists of various vegetables (tomato, carrot, petit vert, kale, red bell pepper, spinach, nalta jute, broccoli, lettuce, celery, ginger, violet cabbage, red perilla, mugwort, bok-choy, cauliflower, watercress, parsley, pumpkin, asparagus, onion, beetroot, white radish, komatsuna, purple sweet potato, Angelica keiskei [ashitaba], Chinese cabbage, eggplant, green peas, and burdock). The nutrient information for the vegetable juice is shown in Table 1 . The experimental meal was commercially available pre-packaged cooked rice (Sato Foods Industries Co., Ltd., Komaki, Japan), which was heated before each experiment and portioned to provide the appropriate quantity of total available carbohydrates for each test.

\subsection{Participants and Design}

The study was divided in two tests, with Test 1 confirming the appropriate timing for drinking the vegetable juice and Test 2 determining the necessary volume of the juice. The study protocols were approved by the Ethics Committee of Josai University and KAGOME CO., LTD. and were performed in accordance with the International Ethical Guidelines and the Declaration of Helsinki. All participants provided their written informed consent to participate in the study.

For each test, we enrolled men and women who were $>20$ years old, did not exhibit abnormal glucose tolerance during the medical check-ups for the previous year, and were not receiving drug therapy. The women did not undergo testing during their menstrual periods. The participants' baseline characteristics according to test are shown in Table 2.

In Test 1 , six experiments were randomly assigned to 8 subjects, which evaluated the response to different amounts of rice and/or different intake times for the vegetable juice (Table 3). Two groups not drinking the 
Table 1. Nutritional information for the vegetable juice from this study.

\begin{tabular}{cc}
\hline Nutrition information (per 200 mL) & 71 \\
Energy (kcal) & 2.1 \\
Protein (g) & 0 \\
Fat (g) & 14.6 \\
Carbohydrate (g) & 11.4 \\
Sugars, total (g) & 5.6 \\
Sucrose (g) & 2.8 \\
Glucose (g) & 3.0 \\
Fructose (g) & 1.9 \\
Dietary fiber (g) & 53 \\
Calcium (mg) & 830 \\
Potassium (mg) & 1190 \\
Citric acid (mg) & 514 \\
Malic acid (mg) & 130 \\
Total polyphenol (mg GAE) & 530 \\
\hline
\end{tabular}

GAE: gallic acid equivalents.

Table 2. Subject characteristics for tests 1 and 2.

\begin{tabular}{|c|c|c|c|c|c|c|}
\hline & \multicolumn{3}{|c|}{ Test 1} & \multicolumn{3}{|c|}{ Test 2} \\
\hline & Total $(\mathrm{n}=8)$ & Men $(n=4)$ & Women $(n=4)$ & Total $(\mathrm{n}=10)$ & Men $(n=7)$ & Women $(\mathrm{n}=3)$ \\
\hline Age (years) & $22.9 \pm 0.8$ & $22.8 \pm 0.4$ & $23.0 \pm 1.0$ & $22.2 \pm 1.8$ & $22.3 \pm 2.0$ & $22.0 \pm 1.4$ \\
\hline Height (cm) & $161.8 \pm 8.9$ & $168.1 \pm 8.2$ & $155.5 \pm 3.5$ & $171.3 \pm 8.5$ & $175.8 \pm 5.7$ & $160.7 \pm 1.7$ \\
\hline Weight (kg) & $54.7 \pm 7.7$ & $59.5 \pm 6.6$ & $50.0 \pm 5.6$ & $61.6 \pm 9.2$ & $66.6 \pm 6.0$ & $50.0 \pm 2.4$ \\
\hline BMI $\left(\mathrm{kg} / \mathrm{m}^{2}\right)$ & $20.9 \pm 2.2$ & $21.0 \pm 1.6$ & $20.7 \pm 2.7$ & $21.2 \pm 2.1$ & $21.6 \pm 2.1$ & $19.4 \pm 0.9$ \\
\hline HbA1c (\%) & $5.3 \pm 0.2$ & $5.2 \pm 0.2$ & $5.4 \pm 0.2$ & $5.2 \pm 0.2$ & $5.2 \pm 0.2$ & $5.4 \pm 0.1$ \\
\hline
\end{tabular}

Data are presented as mean \pm SD. BMI: body mass index; HbA1c: hemoglobin A1C.

Table 3. Experimental design for each group in tests 1 and 2.

\begin{tabular}{|c|c|c|c|c|c|c|c|c|c|c|c|}
\hline & \multicolumn{6}{|c|}{ Test 1} & \multicolumn{5}{|c|}{ Test 2} \\
\hline & Rice 150 & Rice 106 & $0 \mathrm{VJ}$ & $-15 \mathrm{VJ}$ & $-30 \mathrm{VJ}$ & $-60 \mathrm{VJ}$ & Rice 150 & CHO 5 & CHO 10 & CHO 15 & CHO 20 \\
\hline Rice intake (g) & 150 & 106 & 106 & 106 & 106 & 106 & 150 & 135 & 120 & 106 & 90 \\
\hline Vegetable juice intake (mL) & - & - & 200 & 200 & 200 & 200 & - & 68.5 & 137 & 200 & 274 \\
\hline Drinking the juice (min) & - & - & 0 & -15 & -30 & -60 & - & -30 & -30 & -30 & -30 \\
\hline $\begin{array}{l}\text { Blood sampling } \\
\text { before } 0 \text { min (min) }\end{array}$ & - & - & - & -15 & -30 & $-60,-30$ & - & -30 & -30 & -30 & -30 \\
\hline
\end{tabular}

The starting time of consuming the rice was defined as $0 \mathrm{~min}$. VJ: vegetable juice; CHO: carbohydrates.

vegetable juice were named using "Rice" and a number to indicate the grams of administered rice. Four groups drinking the vegetable juice were named using "VJ" and a number to indicate the time of vegetable juice administration before consuming $106 \mathrm{~g}$ of rice. The total amount of available carbohydrates was set to $50 \mathrm{~g}$ in all 
groups, except for in the Rice 106 group (35.4 g). The nutrient components of the test meals for each group are shown in Table 4. Blood samples were taken from the fingertip using a self-administered puncture device. All groups underwent blood sampling at 8 times: immediately before eating the rice or drinking the vegetable juice ( $0 \mathrm{~min}$ ) and then $15 \mathrm{~min}, 30 \mathrm{~min}, 45 \mathrm{~min}, 60 \mathrm{~min}, 90 \mathrm{~min}, 120 \mathrm{~min}$, and $180 \mathrm{~min}$ after eating the rice. The -15 $\mathrm{VJ},-30 \mathrm{VJ}$, and $-60 \mathrm{VJ}$ groups underwent one or two additional blood samplings before eating the rice (Table 3). Immediately after each sampling, the blood glucose levels were measured using a self-administered blood glucose measuring device (Glutest Neo alpha ${ }^{\circledR}$; Sanwa Kagaku Kenkyusho Co. Ltd., Aichi, Japan). In the Rice 150 and $-30 \mathrm{VJ}$ groups, approximately $100 \mu \mathrm{L}$ of extra blood were collected using a capillary tube to measure the plasma insulin concentrations. Plasma was obtained using centrifugation $\left(2610 \times \mathrm{g}, 4^{\circ} \mathrm{C}, 5 \mathrm{~min}\right)$ and kept in a $-80^{\circ} \mathrm{C}$ freezer until testing. The plasma insulin concentrations were measured using a commercially available kit (YK060 Insulin ELISA kit ${ }^{\circledR}$; Yanaihara Institute Inc., Shizuoka, Japan).

In test 2, five experiments were randomly assigned to 10 subjects, which evaluated the response to different amounts of rice and/or different intake volume for the vegetable juice (Table 3). Four groups drinking the vegetable juice were named using "CHO” and a number to indicate the grams of carbohydrate that were administered from the vegetable juice 30 min before consuming $106 \mathrm{~g}$ of rice. The total amount of available carbohydrates was set at $50 \mathrm{~g}$ in all groups, and the nutrient components of the test meal for each group are shown in Table 4. Blood samples were taken 9 times during all experiments: immediately before drinking the vegetable juice ( -30 $\mathrm{min}$ ) and then $0 \mathrm{~min}, 15 \mathrm{~min}, 30 \mathrm{~min}, 45 \mathrm{~min}, 60 \mathrm{~min}, 90 \mathrm{~min}, 120 \mathrm{~min}$, and $180 \mathrm{~min}$ after eating the rice. Immediately after each sampling, blood glucose levels were measured as mentioned in the previous paragraph. Each experiment was performed approximately 1 week apart, and was conducted at the same time in the morning. The day before the experiment, the participants were asked to not consume any foods or drinks (other than water) after 9:00 PM, and the vegetable juice and rice were served after an overnight fast. The vegetable juice was ingested immediately (within $1 \mathrm{~min}$ ) and the rice was consumed within $5 \mathrm{~min}$. In addition to the test meals, $200 \mathrm{~mL}$ of water or hot water was served, and the participants were allowed to drink the water ad libitum during each experiment.

\subsection{Statistical Analysis}

Blood glucose and plasma insulin levels were recorded for each subject, and were used to calculate the $\Delta$ blood glucose and $\Delta$ insulin levels by subtracting the level from before the first meal (vegetable juice or cooked rice). The maximum values for the $\Delta$ blood glucose and $\Delta$ insulin levels were defined as the $\Delta$ maximum concentrations $\left(\Delta \mathrm{C}_{\max }\right)$. The incremental areas under the curves (IAUC) were calculated based on the changes in the $\Delta$ blood glucose and $\Delta$ insulin levels. All statistical calculations were performed using Statcel2 software (OMS Publishing Inc., Saitama, Japan), and differences with a $p$-value of $<0.05$ were considered statistically significant. The results from the $\Delta$ blood glucose were assessed using Dunnett's test, and the results from the analyses of and $\Delta$ insulin analyses were assessed using the paired t-test.

Table 4. Nutrient components of the meals for tests 1 and 2.

\begin{tabular}{|c|c|c|c|c|c|c|c|c|}
\hline & \multicolumn{3}{|c|}{ Test 1} & \multicolumn{5}{|c|}{ Test 2} \\
\hline & Rice 150 & Rice 106 & $\begin{array}{l}0 \mathrm{VJ},-15 \mathrm{VJ}, \\
-30 \mathrm{VJ},-60 \mathrm{VJ}\end{array}$ & Rice 150 & CHO 5 & CHO 10 & CHO15 & CHO 20 \\
\hline Energy (kcal) & 216.8 & 153.5 & 224.5 & 216.8 & 219.4 & 222.0 & 224.5 & 227.4 \\
\hline Carbohydrates (g) & 50.0 & 35.4 & 50.0 & 50.0 & 50.0 & 50.0 & 50.0 & 50.0 \\
\hline from rice (g) & 50.0 & 35.4 & 35.4 & 50.0 & 45.0 & 40.0 & 35.4 & 30.0 \\
\hline from VJ (g) & 0.0 & 0.0 & 14.6 & 0.0 & 5.0 & 10.0 & 14.6 & 20.0 \\
\hline Fat (g) & 0.5 & 0.3 & 0.3 & 0.5 & 0.5 & 0.4 & 0.3 & 0.2 \\
\hline Protein (g) & 3.1 & 2.2 & 4.3 & 3.1 & 3.5 & 3.9 & 4.3 & 4.7 \\
\hline Dietary fiber (g) & 0.5 & 0.3 & 2.2 & 0.5 & 1.1 & 1.7 & 2.2 & 2.9 \\
\hline
\end{tabular}

VJ: vegetable juice; CHO: carbohydrates. 


\section{Results}

\subsection{Test 1: The Effects of Vegetable Juice Intake Timing on Postprandial Blood Glucose and Plasma Insulin Levels}

The time-dependent changes in $\Delta$ blood glucose levels for each group are shown in Figure 1 . The Rice 150 group exhibited an immediate increase after eating the rice, reached a peak at $45 \mathrm{~min}$, and then decreased. The Rice 106 group exhibited lower $\Delta$ blood glucose levels, compared to the Rice 150 group, but the differences at each time point were not statistically significant. The $0 \mathrm{VJ}$ group exhibited essentially the same $\Delta$ blood glucose levels up to $30 \mathrm{~min}$, compared to the Rice 150 group, but the value at 60 min was significantly lower. The $\Delta$ blood glucose levels in the $-15 \mathrm{VJ},-30 \mathrm{VJ},-60 \mathrm{VJ}$ groups increased after drinking the vegetable juice, but the $\Delta$ blood glucose levels in those groups after eating the rice tended to be lower than the corresponding values in the Rice 150 group. The $-15 \mathrm{VJ}$ group exhibited lower $\Delta$ blood glucose levels at $30 \mathrm{~min}, 45 \mathrm{~min}$, and $60 \mathrm{~min}$; the $-30 \mathrm{VJ}$ group exhibited lower $\Delta$ blood glucose levels at $30 \mathrm{~min}$ and $45 \mathrm{~min}$; and the $-60 \mathrm{VJ}$ group exhibited lower $\Delta$ blood glucose levels at $30 \mathrm{~min}$.

The $\Delta \mathrm{C}_{\max }$ values for blood glucose in the $-15 \mathrm{VJ},-30 \mathrm{VJ}$, and $-60 \mathrm{VJ}$ groups were significantly lower than those in the Rice 150 group (Table 5). The IAUC values for blood glucose in the $0 \mathrm{VJ},-15 \mathrm{VJ},-30 \mathrm{VJ}$, and -60 VJ groups tended to be smaller than those in the Rice 150 group, although the differences were not statistically significant (Table 5).

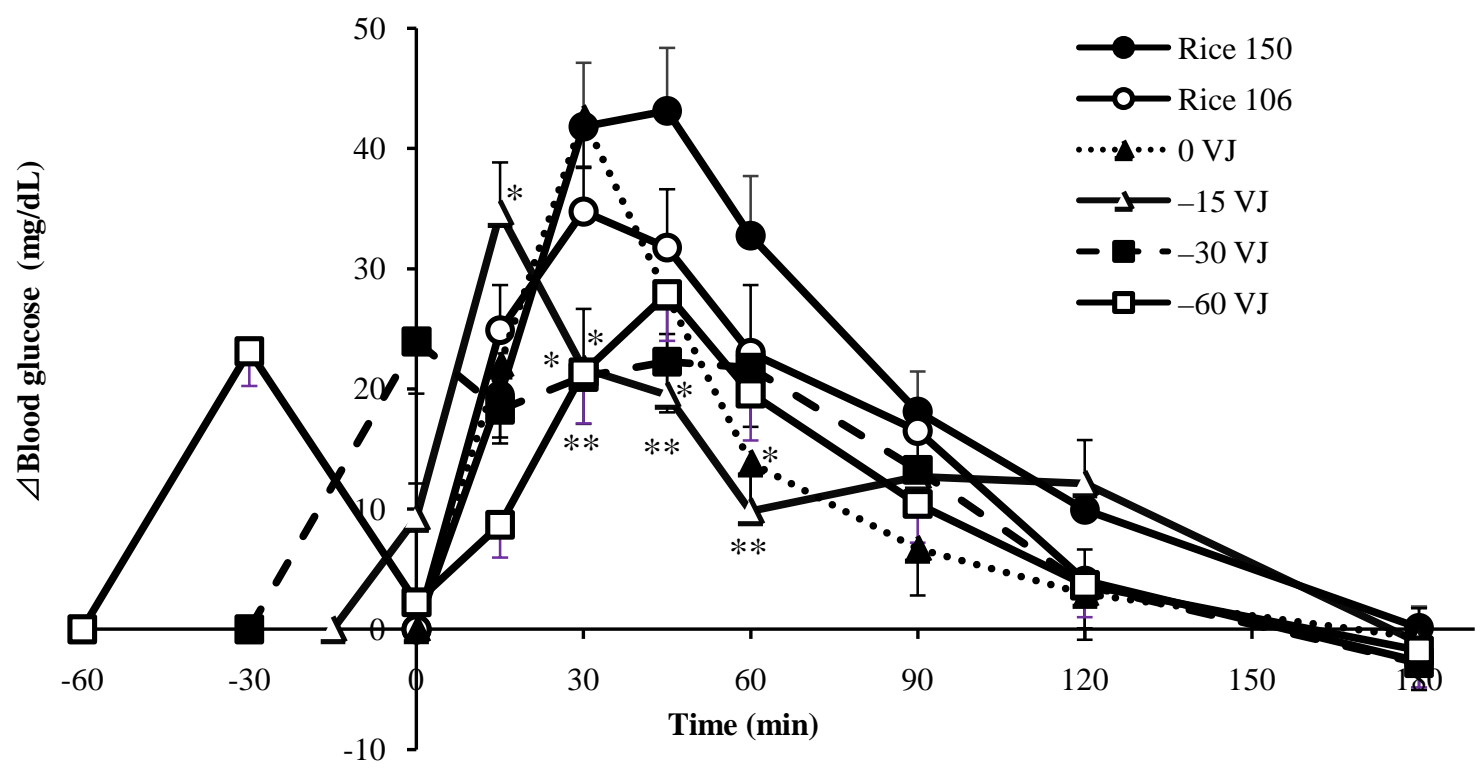

Figure 1. The time-dependent changes in $\Delta$ blood glucose levels in each group during test 1 . Data are presented as mean \pm SE. ${ }^{*} p<0.05$ vs. Rice $150,{ }^{* *} p<0.01$ vs. Rice 150 .

Table 5. Kinetic parameters for postprandial blood glucose in test 1.

\begin{tabular}{ccc}
\hline & IAUC $(\mathrm{mg} \times \mathrm{min} / \mathrm{dL})$ & $\Delta \mathrm{C}_{\max }(\mathrm{mg} / \mathrm{dL})$ \\
\hline Rice 150 & $3322 \pm 976$ & $49.5 \pm 5.2$ \\
Rice 106 & $2637 \pm 787$ & $37.9 \pm 4.6$ \\
$0 \mathrm{VJ}$ & $2552 \pm 1656$ & $44.0 \pm 4.0$ \\
$-15 \mathrm{VJ}$ & $2467 \pm 997$ & $36.3 \pm 4.2^{*}$ \\
$-30 \mathrm{VJ}$ & $2659 \pm 1233$ & $29.7 \pm 2.9^{* *}$ \\
$-60 \mathrm{VJ}$ & $2696 \pm 1123$ & $34.6 \pm 3.8^{*}$ \\
\hline
\end{tabular}

Data are presented as mean \pm SE. ${ }^{*} p<0.05$ vs. Rice $150,{ }^{* *} p<0.01$ vs. Rice 150 ; VJ: vegetable juice timing; IAUC: incremental area under the curve; $\mathrm{C}_{\max }$ : maximum concentration. 
The insulin responses in the Rice 150 group and $-30 \mathrm{VJ}$ group are shown in Figure 2. The $\Delta$ insulin levels in the Rice 150 group increased after consuming the rice and reached a peak at $30 \mathrm{~min}$. The $\Delta$ insulin levels in the $-30 \mathrm{VJ}$ group were elevated after the vegetable juice intake, neared the peak at 0 min, reached the peak at 30 min, and subsequently decreased more quickly than those in the Rice 150 group. The values for plasma insulin $\Delta \mathrm{C}_{\max }$ and IAUC were not significantly different between the groups (Table 6).

\subsection{Test 2: The Effects of Vegetable Juice Ingestion Volume on Postprandial Blood Glucose Levels}

The time-dependent changes in blood glucose levels for each group are shown in Figure 3. The results in the Rice 150 group were almost identical to the results from Test 1 . There were no statistically significant differences when we compared the changes of $\Delta$ blood glucose levels in the carbohydrate (CHO) 5 and $\mathrm{CHO} 10$ groups to those in the Rice 150 group. The $\Delta$ blood glucose levels in the CHO 15 and CHO 20 groups were lower than those in the Rice 150 group at $30 \mathrm{~min}, 45 \mathrm{~min}, 60 \mathrm{~min}$, and $120 \mathrm{~min}$.

The $\Delta \mathrm{C}_{\max }$ value in the CHO 15 group was significantly lower than that in the Rice 150 group (Table 7). The IAUC values in the CHO 15 and CHO 20 groups were significantly lower than that in the Rice 150 group (Table 7).

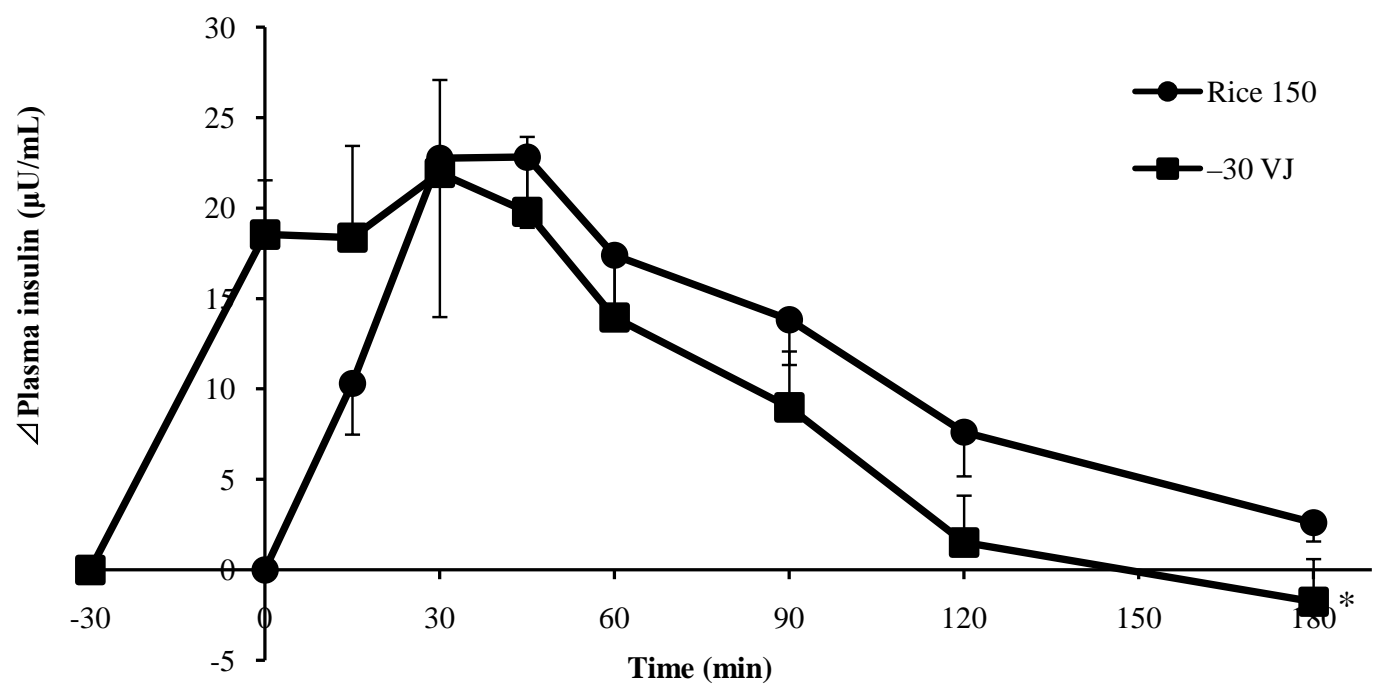

Figure 2. The time-dependent changes in $\Delta$ plasma insulin levels in each group during test 1 . Data are presented as mean \pm SE. ${ }^{*} p<0.05$ vs. Rice 150 .

Table 6. Kinetic parameters of postprandial plasma insulin in test 1.

\begin{tabular}{|c|c|c|}
\hline & IAUC & $\Delta \mathrm{C}_{\max }$ \\
\hline & $(\mu \mathrm{U} \times \min / \mathrm{mL})$ & $(\mu \mathrm{U} / \mathrm{mL})$ \\
\hline Rice 150 & $2072 \pm 380$ & $28.2 \pm 8.0$ \\
\hline$-30 \mathrm{VJ}$ & $2104 \pm 336$ & $29.2 \pm 5.0$ \\
\hline
\end{tabular}

Data are presented as mean \pm SE. VJ: vegetable juice timing; IAUC: incremental area under the curve; $\mathrm{C}_{\max }$ : maximum concentration.

Table 7. Kinetic parameters for postprandial blood glucose in test 2.

\begin{tabular}{ccc} 
& IAUC $(\mathrm{mg} \times \min / \mathrm{dL})$ & $\Delta \mathrm{C}_{\max }(\mathrm{mg} / \mathrm{dL})$ \\
\hline Rice 150 & $4093 \pm 561$ & $44.6 \pm 5.0$ \\
CHO 5 & $3007 \pm 59$ & $36.4 \pm 3.3$ \\
CHO 10 & $3265 \pm 256$ & $41.3 \pm 3.3$ \\
CHO 15 & $2447 \pm 329^{*}$ & $28.1 \pm 2.4^{*}$ \\
CHO 20 & $2299 \pm 478^{*}$ & $33.1 \pm 4.0$ \\
\hline
\end{tabular}

Data are presented as mean \pm SE. ${ }^{*} p<0.05$ vs. Rice 150 . CHO: carbohydrates; IAUC: incremental area under the curve; $\mathrm{C}_{\max }$ : maximum concentration. 


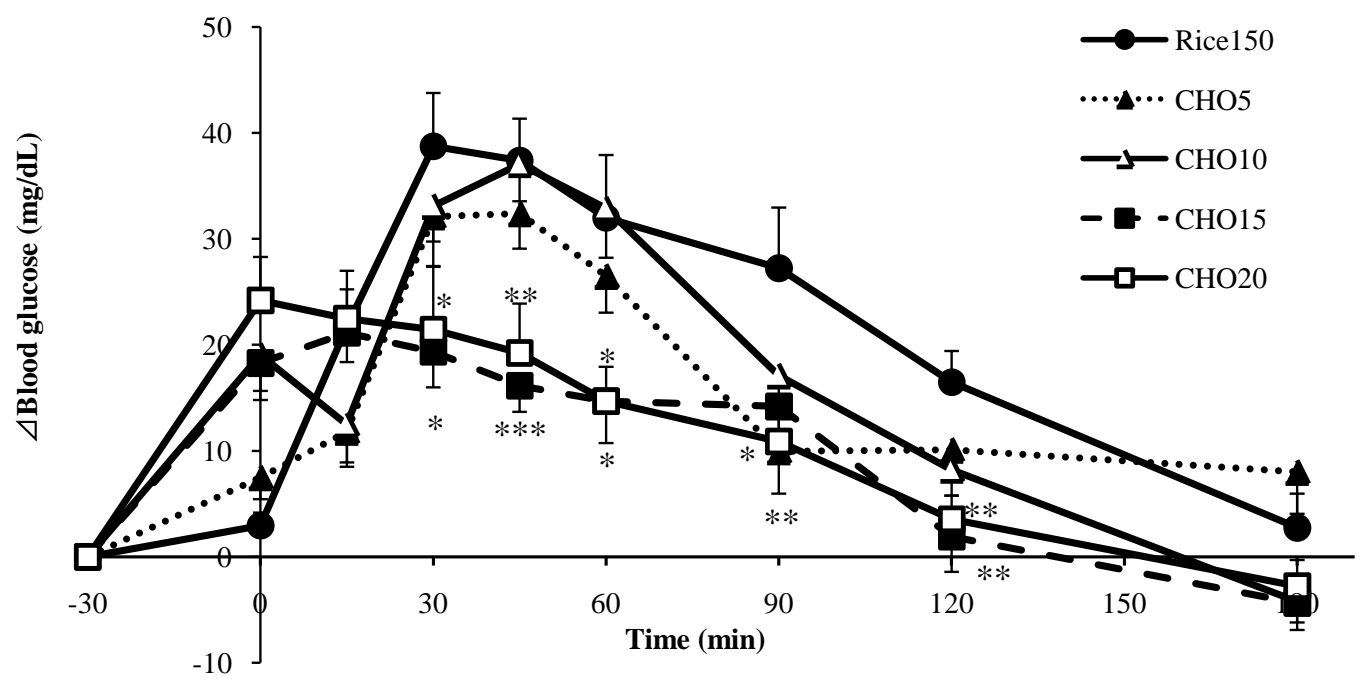

Figure 3. The time-dependent changes in $\Delta$ blood glucose levels in each group during test 2 . Data are presented as mean \pm SE. ${ }^{*} p<0.05$ vs. Rice $150,{ }^{* *} p<0.01$ vs. Rice $150,{ }^{* * *} p<0.001$ vs. Rice 150.

\section{Discussion}

In the present study, we evaluated the effects of vegetable juice consumption on postprandial blood glucose elevation. In Test 1, we examined the effects of intake timing, and the results revealed that drinking the vegetable juice before or with a meal attenuated the postprandial blood glucose levels when the total amount of available carbohydrates was set at $50 \mathrm{~g}$. More interestingly, the $\Delta \mathrm{C}_{\max }$ and IAUC values for blood glucose in the groups that drank the vegetable juice tended to be rather lower than those in the Rice 106 group, despite the total amount of available carbohydrates $(50 \mathrm{~g})$ being approximately 1.4-fold larger than that in the Rice 106 group (35.4 g). These results suggest that the effects of vegetable juice can be expected not only in the case of removing carbohydrates corresponding to vegetable juice from the meal but also in the case of simply adding vegetable juice to the meal.

Postprandial blood glucose levels can become elevated due to poor secretions of insulin and incretin hormones, such as Glucagon-Like Peptide 1 (GLP-1) and Glucose-dependent Insulinotropic Polypeptide (GIP) [21]-[23]. The vegetable juice that we used contains saccharides that are derived from vegetables, (e.g., glucose, sucrose, and fructose), and these saccharides stimulate the secretion of insulin, GLP-1, and GIP [24] [25]. In Test 1 , insulin secretion was stimulated by drinking the vegetable juice at 30 min before eating the rice, and we observed that the plasma insulin levels had nearly peaked at the time of eating the rice. Interestingly, the blood glucose levels exhibited very little increase after eating the rice. Therefore, it appears that the pre-meal drinking of the vegetable juice stimulated insulin secretion, and that the resulting serum insulin levels were sufficient to attenuate the postprandial blood glucose elevation. Based on this result, it appears that vegetable juice consumption may have a unique mechanism for suppressing postprandial blood glucose elevation, compared to the mechanism for vegetable salad consumption, as vegetable salads do not stimulate insulin secretion [18]-[20].

In Test 2, $200 \mathrm{~mL}$ of vegetable juice was the most effective volume for suppressing postprandial blood glucose elevation, and larger volumes of vegetable juice did not provide an additive effect. In this context, increases in the levels of blood glucose and insulin are affected by the types and amounts of carbohydrates [26] [27]. Furthermore, the saccharides in vegetable juice primarily consist of sucrose, glucose, and fructose, while the primary carbohydrate in rice is starch. Although the total amount of available carbohydrates was standardized at 50 $\mathrm{g}$ in test 2, the sources and components of the available carbohydrates were different among the different groups. These differences may partially explain the differences in the suppression of postprandial blood glucose elevation after consuming different volumes of the vegetable juice.

Previous studies have reported that eating a vegetable salad before consuming carbohydrates attenuated the postprandial increase in blood glucose levels [18]-[20]. The mechanism for this attenuation may be related to various mechanisms: 1) dietary fibers in the vegetables slowing the rate of gastric emptying, 2) vinegar (acetic acid) in a dressing slowing the rate of gastric emptying, and/or 3) the high quantity of monounsaturated fatty 
acids in a dressing enhancing insulin sensitivity by stimulating the secretion of GLP-1 [19]. However, the vegetable juice that we used in the present study contained $1.9 \mathrm{~g}$ of dietary fiber per $200 \mathrm{~mL}$, which is more dietary fiber that from the vegetable salad in the previous study [20]. Therefore, dietary fiber in the vegetable juice may be a potent ingredient for suppressing postprandial blood glucose elevation.

Another possible mechanism for the vegetable juice's suppressive effects is that constituents in the vegetable juice inhibited the digestion and absorption of carbohydrates. In this context, carbohydrates are digested and converted to disaccharides by amylase, which is present in saliva and pancreatic juice, and the disaccharides are further hydrolyzed and converted to glucose by glycosidases in the brush border membrane of the intestinal epithelium. Once it is converted in the intestinal epithelium, the glucose is absorbed by sodium-dependent glucose transporter 1 (SGLT 1). Thus, inhibitors of these enzymes may impair carbohydrate digestion and glucose absorption, and suppress postprandial blood glucose elevation. Furthermore, the vegetable juice from the present study contains organic acids, such as citric acid and malic acid, and these organic acids can suppress the activity of carbohydrate digestion enzymes, such as $\alpha$-amylase and $\alpha$-glucosidase [28]-[30]. Moreover, the vegetable juice contained polyphenols. Although the composition of polyphenols in the vegetable juice was not clear in this study, it might contain polyphenols as naringenin, chlorogenic acid, quercetin, and kaempferol because they are present in tomato (the major ingredient of the vegetable juice) [31] [32]. These polyphenols can suppress the activities of $\alpha$-amylase and $\alpha$-glucosidase [33]-[35], and inhibit SGLT 1 [36]-[38]. Thus, it is possible that the organic acids and polyphenols in the vegetable juice may slow glucose absorption by suppressing the activities of $\alpha$-amylase, $\alpha$-glucosidase, and SGLT 1.

The present study revealed that vegetable juice suppressed the elevation of blood glucose levels among healthy young adults, although it is unclear whether this effect could be elicited in patients with diabetes. For example, patients with diabetes exhibit insulin resistance and impaired insulin secretion, and most Japanese cases of diabetes are characterized by decreased insulin secretion [39]. Therefore, given that the vegetable juice stimulated insulin secretion, it is possible that vegetable juice consumption may attenuate postprandial blood glucose elevation among Japanese patients with diabetes.

\section{Conclusion}

We found that drinking vegetable juice before or with a carbohydrate-based meal attenuated the elevation of postprandial blood glucose levels. Moreover, we found that drinking approximately $200 \mathrm{~mL}$ of vegetable juice at 30 min before eating was the most effective way to suppress the elevation of postprandial blood glucose levels. Although the mechanism for this suppression remains unclear, it is possible that the vegetable juice stimulated insulin secretion to decrease blood glucose levels. These results indicate that vegetable juice is a useful substitute for vegetables and a functional food for controlling postprandial blood glucose levels. Therefore, we believe that people can easily control postprandial blood glucose levels by introducing a vegetable juice into their diets, although additional research is needed to determine the precise mechanism(s) for this effect and to confirm whether these effects are elicited in patients with diabetes.

\section{References}

[1] Shaw, J.E., Sicree, R.A. and Zimmet, P.Z. (2010) Global Estimates of the Prevalence of Diabetes for 2010 and 2030. Diabetes Research and Clinical Practice, 87, 4-14. http://dx.doi.org/10.1016/j.diabres.2009.10.007

[2] Diabetes Control and Complications Trial (1993) The Effect of Intensive Treatment of Diabetes on the Development and Progression of Long-Term Complications in Insulin-Dependent Diabetes Mellitus. New England Journal of Medicine, 329, 977-986. http://dx.doi.org/10.1056/NEJM199309303291401

[3] Ohkubo, Y., Kishikawa, H., Araki, E., Miyata, T., Isami, S., Motoyoshi, S., Kojima, Y., Furuyoshi, N. and Shichiri, M. (1995) Intensive Insulin Therapy Prevents the Progression of Diabetic Microvascular Complications in Japanese Patients with Non-Insulin-Dependent Diabetes Mellitus: A Randomized Prospective 6-Year Study. Diabetes Research and Clinical Practice, 28, 103-117. http://dx.doi.org/10.1016/0168-8227(95)01064-K

[4] UK Prospective Diabetes Study (UKPDS) Group (1998) Intensive Blood-Glucose Control with Sulphonylureas or Insulin Compared with Conventional Treatment and Risk of Complications in Patients with Type 2 Diabetes (UKPDS 33). Lancet, 352, 837-853. http://dx.doi.org/10.1016/S0140-6736(98)07019-6

[5] Huxley, R., Barzi, F. and Woodward, M. (2006) Excess Risk of Fatal Coronary Heart Disease Associated with Diabetes in Men and Women: Meta-Analysis of 37 Prospective Cohort Studies. BMJ, 332, 73-78. http://dx.doi.org/10.1136/bmj.38678.389583.7C 
[6] Haffner, S.M., Lehto, S., Rönnemaa, T., Pyörälä, K. and Laakso, M. (1998) Mortality from Coronary Heart Disease in Subjects with Type 2 Diabetes and in Nondiabetic Subjects with and without Prior Myocardial Infarction. New England Journal of Medicine, 339, 229-234. http://dx.doi.org/10.1056/NEJM199807233390404

[7] Monnier, L., Colette, C., Dunseath, G.J. and Owens, D.R. (2007) The Loss of Postprandial Glycemic Control Precedes Stepwise Deterioration of Fasting with Worsening Diabetes. Diabetes Care, 30, 263-269. http://dx.doi.org/10.2337/dc06-1612

[8] Brand-Miller, J., Dickinson, S., Barclay, A. and Celermajer, D. (2007) The Glycemic Index and Cardiovascular Disease Risk. Current Atherosclerosis Reports, 9, 479-485. http://dx.doi.org/10.1007/s11883-007-0064-X

[9] Ludwig, D.S. (2000) Dietary Glycemic Index and Obesity. Journal of Nutrition, 130, 280S-283S.

[10] Gerich, J.E. (2003) Clinical Significance, Pathogenesis, and Management of Postprandial Hyperglycemia. Archives of Internal Medicine, 163, 1306-1316. http://dx.doi.org/10.1001/archinte.163.11.1306

[11] Ma, Y., Olendzki, B., Chiriboga, D., Hebert, J.R., Li, Y., Li, W., Campbell, M., Gendreau, K. and Ockene, I.S. (2005) Association between Dietary Carbohydrates and Body Weight. American Journal of Epidemiology, 161, 359-367. http://dx.doi.org/10.1093/aje/kwi051

[12] Salmerón, J., Ascherio, A., Rimm, E.B., Colditz, G.A., Spiegelman, D., Jenkins, D.J., Stampfer, M.J., Wing, A.L. and Willett, W.C. (1997) Dietary Fiber, Glycemic Load, and Risk of NIDDM in Men. Diabetes Care, 20, 545-550. http://dx.doi.org/10.2337/diacare.20.4.545

[13] Salmerón, J., Manson, J.E., Stampfer, M.J., Colditz, G.A., Wing, A.L. and Willett, W.C. (1997) Dietary Fiber, Glycemic Load, and Risk of Non-Insulin-Dependent Diabetes Mellitus in Women. JAMA, 277, 472-477. http://dx.doi.org/10.1001/jama.1997.03540300040031

[14] Liu, S., Willett, W.C., Stampfer, M.J., Hu, F.B., Franz, M., Sampson, L., Hennekens, C.H. and Manson, J.E. (2000) A Prospective Study of Dietary Glycemic Load, Carbohydrate Intake, and Risk of Coronary Heart Disease in US Women. American Journal of Clinical Nutrition, 71, 1455-1461.

[15] Fontvieille, A.M., Rizkalla, S.W., Penfornis, A., Acosta, M., Bornet, F.R. and Slama, G. (1992) The Use of Low Glycaemic Index Foods Improves Metabolic Control of Diabetic Patients over Five Weeks. Diabetic Medicine, 9, 444-450. http://dx.doi.org/10.1111/j.1464-5491.1992.tb01815.x

[16] Nansel, T.R., Gellar, L. and McGill, A. (2008) Effect of Varying Glycemic Index Meals on Blood Glucose Control Assessed with Continuous Glucose Monitoring in Youth with Type 1 Diabetes on Basal-Bolus Insulin Regimens. Diabetes Care, 31, 695-697. http://dx.doi.org/10.2337/dc07-1879

[17] Slama, G., Elgrably, F., Kabir, M. and Rizkalla, S. (2006) Low Glycemic Index Foods Should Play A Role in Improving Overall Glycemic Control in Type-1 and Type-2 Diabetic Patients and, More Specifically, in Correcting Excessive Postprandial Hyperglycemia. Nestlé Nutrition Workshop Series: Clinical and Performance Program, 11, 73-81. http://dx.doi.org/10.1159/000094407

[18] Kanamoto, I., Inoue, Y., Moriuchi, T., Yamada, Y., Imura, H. and Sato, S. (2010) Effect of Differences in Low Glycemic Index Food Intake Sequence on Plasma Glucose Profile. Journal of the Japan Diabetes Society, 53, 96-101.

[19] Kasuya, N., Ohta, S., Takanami, Y., Kawai, Y., Inoue, Y., Murata, I. and Kanamoto, I. (2015) Effect of Low Glycemic Index Food and Postprandial Exercise on Blood Glucose Level, Oxidative Stress and Antioxidant Capacity. Experimental and Therapeutic Medicine, 9, 1201-1204. http://dx.doi.org/10.3892/etm.2015.2228

[20] Imai, S., Matsuda, M., Miyatani, S., Hasegawa, G., Fukui, M. and Kajiyama, S. (2010) Crossover Study of the Effect of "Vegetable before Carbohydrate" on the Reduction of the Postprandial Glucose and Insulin Levels in Japanese Patients with Type 2 Diabetes Mellitus. Journal of the Japan Diabetes Society, 53, 112-115.

[21] Pratley, R.E. and Weyer, C. (2001) The Role of Impaired Early Insulin Secretion in the Pathogenesis of Type II Diabetes Mellitus. Diabetologia, 44, 929-945. http://dx.doi.org/10.1007/s001250100580

[22] Holst, J.J. and Gromada, J. (2004) Role of Incretin Hormones in the Regulation of Insulin Secretion in Diabetic and Nondiabetic Humans. American Journal of Physiology: Endocrinology and Metabolism, 287, E199-E206. http://dx.doi.org/10.1152/ajpendo.00545.2003

[23] Toft-Nielsen, M.B., Damholt, M.B., Madsbad, S., Hilsted, L.M., Hughes, T.E., Michelsen, B.K. and Holst, J.J. (2001) Determinants of the Impaired Secretion of Glucagon-Like Peptide-1 in Type 2 Diabetic Patients. The Journal of Clinical Endocrinology and Metabolism, 86, 3717-3723. http://dx.doi.org/10.1210/jcem.86.8.7750

[24] Kuhre, R.E., Gribble, F.M., Hartmann, B., Reimann, F., Windeløv, J.A., Rehfeld, J.F. and Holst, J.J. (2014) Fructose Stimulates GLP-1 but Not GIP Secretion in Mice, Rats, and Humans. American Journal of Physiology-Gastrointestinal and Liver Physiology, 306, G622-G630. http://dx.doi.org/10.1152/ajpgi.00372.2013

[25] Maeda, A., Miyagawa, J., Miuchi, M., Nagai, E., Konishi, K., Matsuo, T., Tokuda, M., Kusunoki, Y., Ochi, H., Murai, K., Katsuno, T., Hamaguchi, T., Harano, Y. and Namba, M. (2013) Effects of the Naturally-Occurring Disaccharides, Palatinose and Sucrose, on Incretin Secretion in Healthy Non-Obese Subjects. Journal of Diabetes Investigation, 4, 
281-286. http://dx.doi.org/10.1111/jdi.12045

[26] Wolever, T.M. and Bolognesi, C. (1996) Source and Amount of Carbohydrate Affect Postprandial Glucose and Insulin in Normal Subjects. Journal of Nutrition, 126, 2798-2806.

[27] Brand-Miller, J.C., Thomas, M., Swan, V., Ahmad, Z.I., Petocz, P. and Colagiuri, S. (2003) Physiological Validation of the Concept of Glycemic Load in Lean Young Adults. Journal of Nutrition, 133, 2728-2732.

[28] Ogawa, N., Satsu, H., Watanabe, H., Fukaya, M., Tsukamoto, Y., Miyamoto, Y. and Shimizu, M. (2000) Acetic Acid Suppresses the Increase in Disaccharidase Activity That Occurs during Culture of CaCo-2 Cells. Journal of Nutrition, 130, 507-513.

[29] Hansawasdi, C., Kawabata, J. and Kasai, T. (2001) Hibiscus Acid as an Inhibitor of Starch Digestion in the CaCo-2 Cell Model System. Bioscience, Biotechnology, and Biochemistry, 65, 2087-2089. http://dx.doi.org/10.1271/bbb.65.2087

[30] Hansawasdi, C., Kawabata, J. and Kasai, T. (2000) Alpha-Amylase Inhibitors from Roselle (Hibiscus sabdariffa Linn.) Tea. Bioscience, Biotechnology, and Biochemistry, 64, 1041-1043. http://dx.doi.org/10.1271/bbb.64.1041

[31] Davies, J.N. and Hobson, G.E. (1981) The Constituents of Tomato Fruit-The Influence of Environment, Nutrition, and Genotype. Critical Reviews in Food Science and Nutrition, 15, 205-280. http://dx.doi.org/10.1080/10408398109527317

[32] Martinez-Valverde, I., Periago, M.J., Provan, G. and Chesson, A. (2002) Phenolic Compounds, Lycopene and Antioxidant Activity in Commercial Varieties of Tomato (Lycopersicon esculentum). Journal of the Science of Food and Agriculture, 82, 323-330. http://dx.doi.org/10.1002/jsfa.1035

[33] Pereira, D.F., Cazarolli, L.H., Lavado, C., Mengatto, V., Figueiredo, M.S., Guedes, A., Pizzolatti, M.G. and Silva, F.R. (2011) Effects of Flavonoids on $\alpha$-Glucosidase Activity: Potential Targets for Glucose Homeostasis. Nutrition, 27, 1161-1167. http://dx.doi.org/10.1016/j.nut.2011.01.008

[34] Tadera, K., Minami, Y., Takamatsu, K. and Matsuoka, T. (2006) Inhibition of Alpha-Glucosidase and Alpha-Amylase by Flavonoids. Journal of Nutritional Science and Vitaminology (Tokyo), 52, 149-153. http://dx.doi.org/10.3177/jnsv.52.149

[35] Williamson, G. (2013) Possible Effects of Dietary Polyphenols on Sugar Absorption and Digestion. Molecular Nutrition \& Food Research, 57, 48-57. http://dx.doi.org/10.1002/mnfr.201200511

[36] Welsch, C.A., Lachance, P.A. and Wasserman, B.P. (1989) Dietary Phenolic Compounds: Inhibition of $\mathrm{Na}^{+}$-Dependent D-Glucose Uptake in Rat Intestinal Brush Border Membrane Vesicles. Journal of Nutrition, 119, 1698-1704.

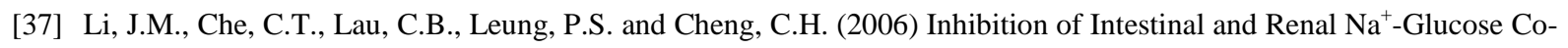
transporter by Naringenin. The International Journal of Biochemistry \& Cell Biology, 38, 985-995. http://dx.doi.org/10.1016/j.biocel.2005.10.002

[38] Bahadoran, Z., Mirmiran, P. and Azizi, F. (2013) Dietary Polyphenols as Potential Nutraceuticals in Management of Diabetes: A Review. Journal of Diabetes \& Metabolic Disorders, 12, 43. http://dx.doi.org/10.1186/2251-6581-12-43

[39] Yoshinaga, H. and Kosaka, K. (1999) Heterogeneous Relationship of Early Insulin Response and Fasting Insulin Level with Development of Non-Insulin-Dependent Diabetes Mellitus in Non-Diabetic Japanese Subjects with or without Obesity. Diabetes Research and Clinical Practice, 44, 129-136. http://dx.doi.org/10.1016/S0168-8227(99)00019-4

\section{Submit or recommend next manuscript to SCIRP and we will provide best service for you:}

Accepting pre-submission inquiries through Email, Facebook, Linkedin, Twitter, etc

A wide selection of journals (inclusive of 9 subjects, more than 200 journals)

Providing a 24-hour high-quality service

User-friendly online submission system

Fair and swift peer-review system

Efficient typesetting and proofreading procedure

Display of the result of downloads and visits, as well as the number of cited articles

Maximum dissemination of your research work

Submit your manuscript at: http://papersubmission.scirp.org/ 